\section{Conference on Industrial Safety}

A Residential conference, to be held at the Royal Hotel, Scarb rough, during October 7-9, is being organised, on behalf of the Association of British Chemica/ Manufacturers, by the Royal Society for the Preveytion of Accidents, to discuss the safe use of solyonts, the installation and maintenance of breathing apparatus, and the use of electrical apparatus in hazardous atmospheres, and similar topics. Sir Harry Jepheott, of Glaxo Laboratories, Ltd., will open the conference, and other speakers will include Dr. A. J. Amor, president of the Association of Industrial Medical Officers; Mr. T. Senior, of Imperial Chemical Industries, Ltd. ; and Mr. S. W. Richards, of the General Electric Company, Ltd. Application forms and full particulars can be obtained from the Royal Society for the Prevention of Accidents, Industrial Safety Division, 131 Sloane Street, London, S.W.1.

\section{Co ference of Foundry Steel Melting}

THE Steel Castings Division of the British Iron and Steel Reslarch Association announces that a conference on foundry steel melting will be held during Septeyher 22-23 at Ashorne Hill, Leamington Spa. The technical and economic aspects of the various processes and their relative merits will be discussed. Following the same procedure as the three previous successful conferences organised by the Steel Castings Division, the conference will consist of four sessions, dealing with the cupola/converter process, electric arc process, other melting processes and general topies, respectively. Application forms for accommodation at Ashorne Hill may be obtained from the Steel Castings Division of the British Iron and Steel Research Association, 11 Park Lane, London, W.1.

\section{Textile Institute Awards}

THE Textile Institute has awarded a $£ 1,000$ open scholarship o Geoffrey Robert Haines, aged nineteen, an engipeering workshop apprentice at Redditch Technjal School, Worcs. This is the first such scholarship offered by the Institute to young persons in any section of the textile industry and to senior sludents in their final year at school. The award will enable Mr. Haines to take a degree course in textile engineering at the Manchester College of Technology.

A further $£ 750$ Cotton Industry War Memorial Trust Scholarship - the seventh-has been awarded by the Institute to John Clifiord Hilton, aged twentyone, a designer at Thos. Moss and Sons, Ltd., Lostock Hall, nr. Preston. Mr. Hilton will complete preparatory studies at the Preston Harris Institute before proceeding to a degree course at the Manchester College of Technology.

\section{Medical Research Council: Travelling Awards}

The Medical Research Council announces that it has mad the following travelling awards for the acadenclc year 1949-50. Rockefeller Travelling Fellowships in Medicine: Mr. W. J. Atkinson, Mackenzie Mackinnon Research Fellow (Royal College of Sargeons), National Hospital, Queen Square, London; Dr. Ruth E. M. Bowden, lecturer in anatomy, Royal Free Hospital School of Medicine, London; Dr. R. Daley, first assistant, Cardiology Department, St. Thomas's Hospital, London; Dr. J. Dawson, lecturer in biochemistry, University of Leeds; Ir. C. E. Lumsden, senior lecturer in pathology, University of Aberdeen; Dr. J. S. Robson, assistant, Departments of Medicine and Clinical Biochemistry, University of Edinburgh. Dorothy Temple Cross Research T ravelling Fellouships in T uberculosis : Dr. A. J. Robertson, medical registrar, Royal Infirmary, Liverpool ; Mr. J. D. Wade, surgical officer, Welsh National Memorial Association (Sully Chest Centre). Travelling Scholarships under an exchange arrange. ment with the Centre National de la Recherche Scientifique in France: Dr. E. J. Field, lecturer in anatomy, University of Bristol ; Miss A. Mi. N. Sewell, Nuffield Research Unit, Psychological Laboratory, University of Cambridge.

\section{The Night Sky in September}

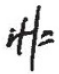

FULL moon occurs on Sept. 7d. C9h. 59m., U.T., and new mogn on Sept. 22, $/ 2 \mathrm{~h}$. 21m. The following conjunctiofs with th moon take place: Sept. 3d 4h. Jupiter 50 N.; Sept. 18d. 22h., Mars $4^{\circ} \mathrm{S}$.; Septenid. 0 h., Saturn $2^{\circ}$ S. ; Sept. 23d. 17h., Mdulury $4^{\circ}$ S.; Sept. 25d. 10h., Venus $1^{\circ}$ N.; Sept. 30d. 10h., Jupiter $5^{\circ}$ N. Mercury is an evening star during the first part of the month and later becomes a morning star, but is too close to the sun for favourable observation. Venus sets about an hour after the sun and can be seen in the western sky, stellar magnitude $-3 \cdot 5$, the visible portion of the illuminated disk being between $0 \cdot 790$ and $0 \cdot 707$. Mars rises just after lh. during the month and can be seen for a few hours before sunrise. Jupiter is visible in the earlier portion of the night, setting at $1 \mathrm{~h} ., 0 \mathrm{~h}$. and $23 \mathrm{~h}$., approximately, at the beginning, middle and end of the month, respectively; the planet is stationary on Sept. 17. Saturn is in conjunction with the sun on Sept. 2 and cannot be observed. Occultations of stars brighter than magnitude 6 are as follows: Sept. 14d. 00h. $35 \cdot 1 \mathrm{~m} ., 36$ Tauri. $(R)$; Sept. I6d. 00h. 05.3m., 136 Tauri. $(R)$; Sept. 18 d. 04h. $15 \cdot \mathrm{lm}$., $\omega$ Canc. $(R) . \quad R$ refers to reappearance and the latitude of Greenwich is assumed. Autumnal equinox occurs on Sept. 23d. 09h.

\section{Announcements}

The Researy Fund of the Chemical Society provides grant for the assistance of research in all branches ff chemistry. About seven hundred pounds per annum is available for this purpose, the income being derived from a donation of the Worshipful Company of Goldsmiths, from the Perkin Memorial Fund, and from other sources. Application forms, obtainable from the General Secretary, The Chemical Society, Burlington House, Piccadilly, London, W.1, should be submitted not later than November 1 . Applications from Fellows of the Society will receive prior consideration.

WE have roleived from Messrs. J. Barcham Green, Ltd., Hay Mill, Maidstone, a sample box of 'Hyduro' filter papers, which have a low ash-content and witbstand pressure-filtering or severe washing withgut bursting. The particular papers examined were double acid-washed, with an average ash per circle of $0.00020 \mathrm{gm}$., and suitable for use with the filter pump for slow filtration with fine precipitates. Other grades are obtainable, one being specially hardened to stand pressures of $30-50 \mathrm{lb}$. wet, which is quite outstanding. 